\title{
LAS COOPERATIVAS EN EL CONTEXTO DE LAS ORGANIZACIONES DE LA ECONOMÍA SOCIAL: BREVE RESEÑA HISTÓRICA. CARACTERÍSTICAS GENERALES
}

"El sistema cooperativo no ha salido del cerebro de un sabio o de un reformador, sino de las entrañas mismas del pueblo"

Charles Gide

\author{
Mgter. Viviana Claudia Pertile \\ E-mail: vpertile@hum.unne.edu.ar \\ Instituto de Geografía- UNNE
}

\section{RESUMEN}

La Economía Social se constituye en una propuesta de una visión estructurada y coherente de múltiples actividades económicas y socio-económicas puesto que involucra una diversidad de factores en la que, las organizaciones del tercer sector juegan un rol importante en la producción total de bienes y servicios en la mayoría de las sociedades occidentales. El cooperativismo en Argentina se ha desarrollado en todas sus formas, respondiendo a diferentes momentos socio-económicos y problemas institucionales del país. A los efectos de indagar sobre esta temática se ha procedido al análisis de la bibliografía disponible sobre el cooperativismo y poder de ese modo reflexionar sobre el rol fundamental que estas desempeñaron en la estructura productiva nacional, regional y provincial.

\section{PALABRAS CLAVES}

Cooperativas.Valores.Principios. Roles

\section{COOPERATIVES IN THE CONTEXT OF SOCIAL ECONOMY ORGANIZATIONS: A BRIEF HISTORY. GENERAL FEATURES.}

\section{ABSTRACT}

The Social Economy constitutes a proposal for a structured and coherent view of multiple economic and socio-economic activities, since it involves a variety of factors in which the third sector organizations play an important role in the total output of goods and services in most Western societies. The cooperative movement in Argentina has been developed in all its forms, responding to different socio-economic periods and institutional problems of the country. To inquire into this topic we analyzed the available literature on cooperativismin order to reflect on the crucial role it has played in the national productive structure, at both regional and provincial levels.

\section{KEYWORDS}

Cooperatives.Values.Principles. Roles 
Revista Geográfica Digital. IGUNNE. Facultad de Humanidades. UNNE. Año 10. № 20.

Julio - Diciembre 2013. ISSN 1668-5180 Resistencia, Chaco

\section{INTRODUCCIÓN}

La Economía Social se manifestó inicialmente en sociedades en transición y particularmente durante las grandes mutaciones del capitalismo. Posteriormente la integración europea y el desmantelamiento de los sistemas centralizados del Este crearon condiciones favorables para que este sector ejerza una doble función: de recuperación y de anticipación. La primera se origina en las reacciones colectivas frente a los problemas que crean las transformaciones del sistema; la segunda, asociada a éstas reacciones, frecuentemente anuncia nuevas demandas sociales y anticipan respuestas más globales.

La Economía Social se constituye en una propuesta de una visión estructurada y coherente de múltiples actividades económicas y socio-económicas, puesto que involucra una diversidad de factores tales como: marcos jurídicos nacionales, dificultades para encontrar términos equivalentes en las diferentes lenguas, pluralidad de tradiciones asociativas y de contextos sociales, culturales y políticos... No obstante ello, numerosos autores coinciden en considerar a la Economía Social como un Tercer gran sector del cual destacan su contribución dada sus funciones específicas.

Al respecto, Michelsen, J. (1997) señala que las organizaciones del tercer sector juegan un rol importante en la producción total de bienes y servicios en la mayoría de las sociedades occidentales, y al mismo tiempo, sostiene que éstas adquieren cada vez mayor interés en los estudios sociológicos y políticos dada su capacidad de unir y articular demandas políticas y sociales como así también por la influencia sobre los procesos que dan origen a las mismas.

Existen diferentes teorías que intentan definir los alcances de las organizaciones del tercer sector:

- la teoría económica neo-institucional (en la línea interpretativa de Ben-Ner, A. y Van Hoomissen, T. y Gui, B.) citados por Michelsen, J. (op. cit.), basa su interpretación en la forma en que las organizaciones del tercer sector abordan las demandas de bienes y servicios o en las relaciones económicas entre los agentes dentro de éstas organizaciones. Estos enfoques hacen hincapié en el aspecto empresarial de dichas organizaciones, mientras que los aspectos organizacionales son principalmente analizados en la medida que ejercen alguna influencia sobre el funcionamiento de la empresa;

- el enfoque de Klausen es más amplio, ya que combina explícitamente un enfoque económico con la Sociología y la teoría organizacional, asignándole a ambas dimensiones igual importancia. De allí que para el autor las organizaciones del tercer sector no son sólo organizaciones sin fines de lucro, sino también privadas basadas en la pertenencia voluntaria de los miembros y orientadas hacia el no-lucro.

Según Jaques Defourny (1987) el sector de la Economía Social o tercer sector, reúne esencialmente las actividades económicas de "organizaciones cooperativas, mutualistas y asociativas".

Actualmente las organizaciones tienen la necesidad de romper con el pasado y satisfacer las nuevas demandas de una economía global y de la sociedad post-capitalista, post-moderna y post-industrial. Estas transformaciones marcan la necesidad de un cambio. En general, el tema es que los precursores de la globalización han aumentado la competencia y la capacidad de depender de un flujo de vastas cantidades de información. De allí que, para la supervivencia sea necesario aumentar la capacidad de respuesta y de flexibilidad de las estructuras organizacionales. Brown, Craig y Ketilson (1995)

Para ciertas organizaciones, tales como las cooperativas, los cambios en la dirección del trabajo en equipo, la participación genuina (en lugar de gerenciada), un menor número de rígidas demarcaciones de los puestos y habilidades de trabajo, la flexibilidad, la capacidad de respuesta a las necesidades, etc. pueden encontrar los valores adoptados por

Publicado en formato digital: Mgter. Viviana Claudia Pertile. LAS COOPERATIVAS EN EL CONTEXTO DE LAS ORGANIZACIONES DE LA ECONOMÍA SOCIAL: BREVE RESEÑA HISTÓRICA. CARACTERÍSTICAS GENERALES. Revista Geográfica Digital. IGUNNE. Facultad de Humanidades. UNNE. Año 10. No 20. Julio Diciembre 2013. ISSN 1668-5180 Resistencia, Chaco. En: http://hum.unne.edu.ar/revistas/geoweb/default.htm 
la organización. Estos valores pueden incluir no sólo la productividad y la competitividad, sino también valores comunitarios, de sustentabilidad, de prosperidad global y de genuina participación de los trabajadores.

\section{Objetivos:}

El presente trabajo intenta averiguar acerca del significado y alcance del concepto de Cooperativas, en los que intervienen diferentes concepciones y posiciones respecto a las mismas; avanzando luego en el conocimiento de los valores y principios organizacionales de las cooperativas en virtud del espacio que ocupa la Economía Social; para culminar con los orígenes del cooperativismo, particularmente en Argentina y en la provincia del Chaco

\section{Metodología}

Desde el punto de vista metodológico hemos llevado a cabo en esta instancia una investigación documental, apoyándonos en fuentes de carácter documental, obtenidas a través de fuentes bibliográficas, hemerográficas o archivísticas.

\section{Resultados}

\section{Significado y alcance del cooperativismo}

Para llegar a delimitar claramente el concepto, alcance y naturaleza de las cooperativas, según nuestro entender, debemos comenzar por definir que es una cooperativa. La Real Academia Española (RAE) considera que una definición es una proposición que expone con claridad y exactitud los caracteres genéricos y diferenciales de algo material o inmaterial. Para la RAE, la cooperativa es entonces, una agrupación natural o pactada de personas, que constituyen unidad distinta de cada uno de sus individuos, con el fin de cumplir, mediante la mutua cooperación, todos o alguno de los fines de la vida.

Yohanan Stryjan (1992) sostiene que, históricamente las cooperativas han sido difíciles de definir y delimitar, existiendo en consecuencia, formas híbridas, definiciones divergentes y límites disputados. A pesar de ello, se puede decir que el movimiento cooperativo tiene una larga historia intelectual, caracterizado por grandes aportes de teóricos de distintas partes del mundo. De lo que no se puede dudar, al decir de Drimer y Drimer (1981), es el origen popular de las organizaciones cooperativas, ya que representaron unas de las formas de organización de vastos sectores frente a graves problemas económico- sociales, que los afligían, tales como los bajos salarios, las condiciones infrahumanas de trabajo, el creciente endeudamiento, el desempleo, etc.

Las cooperativas surgieron muchas veces espontáneamente, gracias al esfuerzo de diversos grupos de consumidores, de trabajadores o de pequeños y medianos productores, inspirados en las tradiciones de asociaciones y de ayuda mutua, que dan origen también a las instituciones de socorros mutuos, a entidades de resistencia u otras organizaciones de carácter popular.

Paralelamente a estas acciones de espontaneidad, se fue gestando el pensamiento de los teóricos, doctrinarios y reformadores sociales que inspiraron y alentaron esas iniciativas.

Se puede decir, que las teorías cooperativistas tienen sus raíces en los primeros años del siglo XIX (1) en Europa y está vinculada con las corrientes de pensamiento predominantes de la época. Debemos entonces referirnos a los escritos de Robert Owen, Charles Fourirer, Charles Gide, y William King, entre otros. Posteriormente, en 1856 el 
historiador Holyoake, proporciona un análisis de la concepción colectiva de las cooperativas, sosteniendo que se tratan de una acción conjunta para resolver los problemas comunes y satisfacer las necesidades comunes de los socios, combinando las características de las organizaciones voluntarias -democráticas- y las empresas de negocios.

Robert Owen, no solo fue cooperativista, sino que también fue autor de numerosos ensayos, sociales y económicos, tendiente a mitigar lo que él denominaba "males del mundo capitalista", en pleno desarrollo. Sobre estas bases fundó sus teorías cooperativistas; asimismo, fue también creador de las cooperativas de consumo y de producción, que se han servido para demostrar que el comerciante y el fabricante no son indispensables. (Grela, 1965)

Charles Gide (2), idealizaba a las cooperativas, en una conferencia pronunciada en 1888, en presencia de casi la totalidad de delegados de las sociedades de cooperativas de París decía: "Puede afirmarse, en homenaje a la naturaleza humana, que los pueblos no se agitan sino por las ideas que se hallan por encima de las finalidades prácticas, y que ellos no entregan su corazón y su fe sino a lo que representa un ideal, seguidamente se preguntaba, ¿existe este ideal en la asociación cooperativa? Yo pienso que sí. Creo que ella debe ser considerada como una forma de organización superior al actual régimen económico y destinada a reemplazarlo..." (Grela, op.cit). Si bien Gide se pronunciaba al respecto, nunca enunció una definición de cooperativa, pero si, ha señalado, luego de analizar los distintos tipos de cooperativas, los rasgos comunes que las caracterizan:

- "Tienen por fin la emancipación económica de ciertas categorías de personas, con el objeto de que puedan ahorrarse los intermediarios y bastarse a sí mismas.

- Sustituir la competencia por la solidaridad.

- No abolir la propiedad individual, sino generalizarla haciéndola asequibles a todos y crear paralelamente una propiedad colectiva.

- No suprimir el capital, sino quitarle el papel preponderante.

- Tener un gran valor educativo" (Gide, op. Cit.)

Así, desde principios y hasta mediados del siglo XIX, las cooperativas florecieron en todo el mundo, tal como lo señala Fairbairn (1995): “...Las cooperativas eran un mecanismo de realimentación entre las personas y su medio ambiente económico".

Charles Fourier (3), fue uno de los doctrinarios más discutidos; sus escritos tenían un alto contenido de extravagancias y divagaciones, pero también ideas progresistas. A semejanza de Owen, consideró que la asociación de personas en colonias autónomas o en comunidades agrícola industriales, sería la solución para numerosos problemas sociales. Si bien Fourier no fue enemigo del capitalismo, si lo fue del industrialismo; propuso reducir a lo indispensable el trabajo en los talleres y darle mayor importancia al trabajo de la tierra, fundamentalmente a la horticultura, la avicultura, la jardinería, entre otras. A diferencia de Owen, Fourier nunca pensó en borrar de sus colonias las desigualdades entre ricos y pobres, de manera que dentro de sus falansterios existían cinco categorías de vivienda y pensión, además de una clase de carácter gratuito.

Fourier al igual que Owen, propiciaron las colonias integrales de producción y consumo que, calificadas por mucho tiempo como utópicas, se volvieron ha hacer realidad tanto en el viejo como en el nuevo mundo (Kibutzim, Koljozes).

William King, se propuso liberar a los trabajadores de la miseria y de su dependencia del capital ajeno. Sostenía que aún cuando los trabajadores son los únicos legítimos dueños de su fuerza de trabajo, no pueden utilizar tal fuerza en su provecho, porque carecen de

Publicado en formato digital: Mgter. Viviana Claudia Pertile. LAS COOPERATIVAS EN EL CONTEXTO DE LAS ORGANIZACIONES DE LA ECONOMÍA SOCIAL: BREVE RESEÑA HISTÓRICA. CARACTERÍSTICAS GENERALES. Revista Geográfica Digital. IGUNNE. Facultad de Humanidades. UNNE. Año 10. No 20. Julio Diciembre 2013. ISSN 1668-5180 Resistencia, Chaco. En: http://hum.unne.edu.ar/revistas/geoweb/default.htm 
capital, sobre todo de capital necesario para alimentarse, vestirse y alojarse hasta que terminan y colocan los artículos que ellos mismos producen.

No solo fue partidario de las cooperativas, sino también de los sindicatos, las mutualidades y otras formas de acción de los trabajadores. Desde el punto de vista práctico, fundó en la ciudad de Brighton, Gran Bretaña, una cooperativa de consumo; rápidamente se organizaron alrededor de trescientas entidades semejantes. Pese a ello, su obra fue efímera y demostró ciertas debilidades en algunas normas que regían el funcionamiento de dichas entidades

El papel que desempeñó William King como precursor del movimiento cooperativista se destaca en algunos de los siguientes aspectos:

- Realzó la importancia del esfuerzo propio de los asociados para proporcionarse los capitales necesarios y solucionar sus problemas comunes.

- Señaló la trascendencia de las cooperativas de consumo como posible base de trasformación de la sociedad y destacó su proyección hacia las actividades productivas.

- Advirtió la influencia no solo económica sino espiritual del cooperativismo, pues confió en que los intereses comunes habrían de determinar relaciones humanas más cordiales. Drimer y Drimer (Op. Cit)

A principios del Siglo XX, la teoría de la cooperativa fue ampliamente debatida por diversos y numerosos académicos europeos. Es Lambert $(4)^{1}$ quien proporciona, a partir de este debate, una definición, que permite comprender el significado de una sociedad cooperativa: ".es una empresa formada y dirigida por una asociación de usuarios, aplicando las reglas de la democracia, cuya directa intención es servir tanto a sus socios como a la comunidad toda".

A esta definición se agregan las suposiciones de Nilsson $(5)^{2}$, que radicaban en el hecho de considerar que la masa societaria de la cooperativa estaría compuesta por personas social y geográficamente cercanas, reunidas para solucionar problemas comunes. Cabe destacar que, para la primera mitad del siglo XX esta premisa, la interacción cara-acara y las necesidades comunes, constituyeron la base aceptada sobre la cual se organizaron y condujeron las cooperativas de consumidores. En efecto, la teoría de la cooperativa tendió a reflejar y promover esta premisa, hasta la primera mitad del siglo XX, donde se produjeron cambios dramáticos en el medio ambiente social, económico y político.

Así, a partir de tales cambios, la práctica cooperativa se modificó para reflejar el mercado cambiante y tendió a imitar la competencia, pasando, el consumismo, la comercialización masiva, el individualismo y las economías de gran escala a ser las fuerzas que movilizaron la gerencia. La teoría cooperativa principal también se vio modificada en su intento por adaptarse a los cambios de la masa societaria cooperativa que se ha tornado más heterogénea, más geográficamente dispersa y con una mentalidad más orientada a los consumidores.

De más está decir que el concepto de cooperativas varió a partir de dichos cambios, pasando a ser consideradas como organizaciones que suministran bienes y servicios a consumidores individuales a fin de satisfacer sus necesidades; comprendiendo dos características: la asociación y los negocios, en efecto, las cooperativas consideraron ventajoso separar la democracia y la participación del lado de negocios de la cooperativa y

\footnotetext{
${ }^{1}$ En Brown L.; Craig, J; Ketilson, L. (op. cit.).

${ }^{2}$ En Brown L.; Craig, J; Ketilson, L. (op. cit.).
} 
fijar una jerarquía de importancia, en donde predominó el lado de los negocios y las dimensiones sociales se consideraron meras actividades de las que se podía prescindir.

Tal como lo expresan Brown, Craig y Ketilson (op. cit.) los teóricos del cooperativismo desarrollaron teorías de administración, en paralelo con la teoría de la administración en general, considerándose que para tener éxito en un ambiente competitivo era necesario un aumento de la eficiencia, lo cual se podía lograr mediante la combinación de una buena administración -directorio y gerencia profesional- con economía de escala. Desplazamiento que reforzó y amplió los cambios en la práctica de las cooperativas y pareció funcionar. Así, desde la década de 1960 a la de 1980, las cooperativas transformaron sus estructuras y lograron éxitos significativos en los negocios.

No obstante, en la década de 1980 las ganancias producidas por los negocios comenzaron a reducirse y en algunas partes del mundo las cooperativas comenzaron a experimentar importantes dificultades.

Esto ha llevado a plantear varios interrogantes en torno a las cooperativas, interrogantes que, si bien son planteados por diversos cooperativistas y teóricos del cooperativismo, compartimos ampliamente: ¿deben las cooperativas estar más o menos orientadas hacia los socios en sentido de aumentar los canales de la participación y las oportunidades democráticas o deben convertirse en mejores negocios en el sentido convencional?, ¿en qué medida las buenas prácticas convencionales de negocios son complementarias o perjudiciales para las cooperativas?; para un excelente negocio cooperativo, ¿es de fundamental importancia el lado de los negocios o el lado de la asociación integral?, ¿existen peligros en que se descuide la educación cooperativa y la democracia participativa para los "socios/propietarios" y en que los "socios/clientes" cultiven los criterios de juicio consumista?

En este sentido, las teorías cooperativistas, están comenzando a rever estas cuestiones, relacionándolas no sólo con la literatura cooperativista, sino también con las nuevas corrientes de la teoría de la administración, que argumentan que una buena administración en la década del '90 significa descentralización, organizaciones flujo dinámicas, flexibilidad, capacidad de respuesta hacia los clientes y una sensibilidad para los problemas de recursos humanos.

Además, quedan como cuestiones cruciales a resolver, la separación entre asociación y empresa -dualismo de la organización cooperativa- y la devaluación del lado social y democrático de las cooperativas. El intento de balancear los dos aspectos de las cooperativas es un error, tanto para la supervivencia del espíritu de las cooperativas como para la supervivencia como negocio, por lo que, es necesario reconceptualizar dicha relación, en el sentido de que no debe predominar el lado social ni tampoco el empresario, sino que ambos deben estar en mutua relación. "Toda cooperativa es una simbiosis: una unión entre una asociación de personas y un negocio, debiendo mantenerse ambos componentes en condiciones saludables para que este organismo prospere...". (Fairbairn: op. cit.). Sin embargo, las relaciones entre estos dos aspectos de las cooperativas no siempre son simbióticas, a veces son antagónicas; lo cual lleva a concluir que las teorías han exagerado los antagonismos y han subestimado la simbiosis.

En síntesis, se puede decir que "las cooperativas son, a la vez, asociaciones de personas y organizaciones de negocios, por lo tanto, para sobrevivir como cooperativas deben fijarse tanto en objetivos de negocios como sociales. Ambos tipos de objetivos no están en conflicto sino interrelacionados de modo complejo -y dinámico-. Los objetivos sociales es improbable que puedan realizarse a menos que el negocio sea efectivo y viable. De modo similar, los objetivos de negocios se refuerzan cuando las cooperativas atienden activamente sus objetivos sociales". (Brown, Craig y Ketilson: op. cit.). 
Al respecto Milchelsen (op. cit.) argumenta que las cooperativas combinan dos tipos de organización: una empresa que actúa en el mercado y una asociación de miembros civiles. El desafío teórico aparece entonces como resultado de la integración de dos tipos de organización con objetivos completamente diferentes: típicas empresas que persiguen la máxima ganancia y típicas asociaciones que persiguen fines orientados a los valores, relegando las consideraciones económicas a un espacio limitado.

En este sentido, conviene tener en cuenta que:

1. Las cooperativas son diferentes de otros tipos de negocios: en efecto, las cooperativas deben diferenciar su forma de empresa económica de las que pertenecen a otros actores económicos, logrando una aceptación pública de ese rol. Las cooperativas difieren de las compañías convencionales en cuanto a sus principios operativos, la legislación bajo las cuales operan y por la forma de adquisición y uso de capitales. Siendo importante, por ello, poseer un sentido claro de la misión, de la naturaleza de la propia organización como cooperativa, de las cualidades que les son únicas, no debiendo olvidarse que primero y principalmente son organizaciones de ayuda mutua.

2. Auspiciar los vínculos con otras organizaciones: esto es, con organizaciones compatibles -proveedores, grupos de trabajadores, organizaciones comunitarias, otras cooperativas-.

3. Desarrollar estilos y técnicas de administración cooperativa: en este sentido se incluyen aspectos tales como involucrar a los socios en la financiación de su cooperativa, dar substancia a la retórica democrática de las cooperativas, reconocer que cualquier cooperativa tiene múltiples veedores y tenedores de intereses; aprovechar al máximo los recursos humanos de los socios y el personal. Para lo cual es necesario, contar con habilidades gerenciales, coherentes con valores y principios democráticos.

Este compromiso de los socios y el aumento de probabilidad de que haya altos niveles de participación, tiene relación directa con facilitar el carácter democrático. En tal sentido, las cooperativas deben, entre otras cosas, cultivar adecuados estilos y valores de liderazgo, desarrollar un rango de canales de comunicación que permita que la misma se desarrolle de arriba hacia abajo y de abajo hacia arriba; establecer un mecanismo para la evaluación regular de las metas sociales,...

En consecuencia, el mayor desafío para las organizaciones cooperativas es el de mantenerse al tanto y adaptarse a las necesidades de sus asociados actuales, y de los que esperan tener en un futuro, lo cual presupone un grado de receptividad considerable por parte de la organización, pero también la capacidad de mantener un intercambio continuo con sus miembros, donde nuevos servicios son definidos y probados, y donde se modelan las precondiciones para una demanda futura. (Stryjan, Y.: op. cit.).

Es la perspectiva de reproducción la que propone una visión de las organizaciones cooperativas como un emprendimiento continuo, un proyecto que debe ser reinventado cotidianamente, por lo que, no existe "receta" correcta ni respuestas categóricas a la cuestión de la organización de la cooperativa, puesto que las soluciones concretas son siempre específicas de una situación y deberían ser desarrolladas por los propios participantes.

Para finalizar y en un intento de articular lo antes dicho, se define a la cooperativa como: “...una asociación autónoma de personas que se han unido de forma voluntaria para satisfacer sus necesidades y aspiraciones económicas, sociales y culturales en común 
mediante una empresa de propiedad conjunta y de gestión democrática". (ICA 1995)(6) ${ }^{3}$ ). Definición en la que quedan formalmente expuestas, las características de una cooperativa:

- La cooperativa es autónoma.

- Es una asociación de personas.

- Las personas se unen voluntariamente.

- Los socios satisfacen sus necesidades económicas, sociales y culturales en común.

- Es una empresa de propiedad conjunta y de gestión democrática.

\section{Valores y Principios de las Organizaciones Cooperativas}

Tal como lo señala el documento del ICA (op. cit.), desde 1988 la Alianza Internacional ha emprendido una revisión mundial de los valores y principios sobre los que las cooperativas basan sus actividades, con el fin de fortalecer la identidad y el papel de las mismas en la economía global.

- Valores

Primera Frase: "Las cooperativas están basadas en los valores de la autoayuda, la autorresponsabilidad, la democracia, la igualdad, la equidad y la solidaridad".

Con respecto a la autoayuda, los cooperativistas creen, que el desarrollo individual pleno solamente puede producirse en asociación con los demás. A través de la acción conjunta y de la responsabilidad mutua se puede llegar a conseguir más, especialmente aumentando la influencia colectiva de uno en el mercado y ante los gobiernos. Además, los individuos también se desarrollan como personas mediante la acción cooperativa debido a las habilidades que adquieren al facilitar el crecimiento de su cooperativa, al conocimiento que consiguen de sus consocios y a las nuevas percepciones que alcanzan sobre la sociedad más amplia de la que forman parte. A este respecto, las cooperativas son instituciones que fomentan la educación y el desarrollo continuos de todos los actores implicados.

Por su parte, la autorresponsabilidad, hace referencia a que los socios asumen responsabilidades de su cooperativa, tanto de su fundación como de su vida continua, siendo los responsables directos de promover su cooperativa entre sus amigos, conocidos y de asegurarse que su cooperativa permanece independiente de otras organizaciones públicas o privadas.

Las cooperativas están basadas en la igualdad, en este sentido, la unidad básica de la cooperativa es el socio -individuo o agrupación de individuos-, esta fundamentación en la persona humana es una de las principales características que distingue a una cooperativa de las empresas orientadas principalmente en beneficio del capital. Ellos deberían estar asociados de la forma más igualitaria posible, teniendo el derecho de participación, de ser informados, de ser escuchados, y de estar involucrados en la toma de decisiones.

En cuanto a la equidad, se refiere a cómo se trata a los socios en una cooperativa. Deberían ser tratados equitativamente en cuanto a la forma de recompensar su participación en la misma, con lo cual, se busca distribuir ganancias o riquezas en base a la contribución y no a la especulación.

El último valor operativo es la solidaridad; valor que asegura que la acción cooperativa no es simplemente una forma disfrazada de interés personal limitado, es decir, que una cooperativa es más que una asociación de socios, es también una colectividad. De allí que la cooperativa tenga una responsabilidad con el interés colectivo de sus socios. Además, la solidaridad significa que los cooperativistas y las cooperativas se mantienen unidos, aspira a la creación de un movimiento cooperativo unido, local, nacional, regional e

\footnotetext{
${ }^{3}$ ICA (1995). Declaración de la Alianza Cooperativa Internacional sobre la identidad Cooperativa. Los principios cooperativos. Edición del Consejo Superior de Cooperativas de Euskadi.
}

Publicado en formato digital: Mgter. Viviana Claudia Pertile. LAS COOPERATIVAS EN EL CONTEXTO DE LAS ORGANIZACIONES DE LA ECONOMÍA SOCIAL: BREVE RESEÑA HISTÓRICA. CARACTERÍSTICAS GENERALES. Revista Geográfica Digital. IGUNNE. Facultad de Humanidades. UNNE. Año 10. № 20. Julio Diciembre 2013. ISSN 1668-5180 Resistencia, Chaco. En: http://hum.unne.edu.ar/revistas/geoweb/default.htm 
internacionalmente. Finalmente, hay que resaltar que la solidaridad es la misma causa y consecuencia de la autoayuda y la ayuda mutua, dos conceptos fundamentales de las cooperativas.

Segunda Frase: "Siguiendo la tradición de sus fundadores, los socios cooperativos hacen suyos los valores éticos de la honestidad, la transparencia, la responsabilidad y la vocación sociales".

Siguiendo la tradición de sus fundadores se refiere al hecho de que en todos los grandes movimientos existen, en su origen, individuos que realizaron aportaciones sobresalientes como "fundadores", por lo que, son venerados y admirados por los cooperativistas de diversos movimientos.

La honestidad hace referencia al hecho de que los esfuerzos de las cooperativas se distinguían en el mercado porque insistieron en el uso de pesos y medidas correctas, alta calidad y precios justos. El trato honesto con sus socios, es lo que tiende a la transparencia, puesto que son organizaciones que regularmente revelan a sus miembros, al público y a los gobiernos una considerable información sobre sus operaciones.

Por su parte, los dos últimos valores emanan de las relaciones especiales que las cooperativas tienen con sus comunidades, en el sentido de que están abiertas a los miembros de esas comunidades, y tienen un compromiso de colaborar con los individuos a ayudarse a sí mismos.

\section{- Principios}

En primer término cabe aclarar que los principios son pautas para evaluar el comportamiento y tomar decisiones, en tal sentido, son marcos de actuación capacitadores a través de los cuales las cooperativas pueden alcanzar el futuro. Los principios que constituyen las cooperativas no son independientes el uno del otro. Están unidos sutil y dinámicamente. Por lo que, en el momento de evaluar una cooperativa, se debe tener en cuenta, cómo se adhieren a los principios en su totalidad.

Se podría resumir diciendo que "en su conjunto, los principios cooperativos son la parte vital del movimiento cooperativo. Derivados de los valores que ha infundido el movimiento desde sus orígenes, conforman las estructuras y determinan las actitudes que proporcionan las perspectivas características del movimiento. Son las pautas mediante las cuales los cooperativistas se esfuerzan por desarrollar sus organizaciones cooperativas. Son principios prácticos en sí mismos, creados tanto por la experiencia de generaciones como por el pensamiento filosófico. Son, por consiguiente, flexibles, aplicables con diferentes grados de detalle en diferentes tipos de cooperativas en distintas situaciones. Por encima de todo, requieren que los cooperativistas tomen decisiones... son las cualidades esenciales que hacen que los cooperativistas sean eficaces, las cooperativas diferentes y el movimiento cooperativo valioso". (ICA: op. cit.).

Entre los principios de las cooperativas, destacados por el ICA, se mencionan: adhesión voluntaria y abierta, gestión democrática por parte de los socios -participación económica de los socios-; autonomía e independencia, educación, formación e información, cooperación entre cooperativas, e interés por la comunidad. Los tres primeros principios se dirigen a la dinámica interna típica de cualquier cooperativa, mientras que los cuatro últimos se dirigen tanto al funcionamiento interno como a las relaciones externas de las cooperativas.

- "Adhesión voluntaria abierta": explica que las cooperativas son organizaciones voluntarias, es decir, que la gente elige voluntariamente comprometerse con sus cooperativas. Las cooperativas están abiertas a todas las personas capaces de utilizar sus servicios y dispuestas a aceptar las responsabilidades de ser socio, sin discriminación de sexo, social, racial, política o religiosa. Además, las cooperativas se organizan para fines 
Revista Geográfica Digital. IGUNNE. Facultad de Humanidades. UNNE. Año 10. № 20. Julio - Diciembre 2013. ISSN 1668-5180 Resistencia, Chaco

específicos, es decir, que puede haber razones comprensibles y aceptables por las que una cooperativa impone límites sobre quiénes pueden ser socios. Por otra parte, los socios tienen obligaciones con su cooperativa, si bien, tales obligaciones difieren de una cooperativa a otra, en general incluyen el ejercicio del derecho de voto, la participación en las reuniones, la utilización de los servicios y la aportación del capital cuando sea necesario. Este principio está estrechamente unido con el principio de la educación y el principio de gestión democrática por parte de los socios, puesto que se considera que éstos últimos, solamente pueden desempeñar su papel si están informados y si hay comunicación eficaz entre los socios, líderes elegidos, directivos y empleados, si los hay.

En definitiva, el principio de adhesión significa que debería haber una relación especial entre la cooperativa y la gente a la que sirve esencialmente, relación que debería definir los negocios realizados por la cooperativa, afectar a la forma en la que los hace y conformar sus planes para el futuro.

- "Gestión democrática por parte de los socios" en las cooperativas la democracia significa, por una parte, considerar los derechos y responsabilidades que poseerán los individuos; y por otra, fomentar el espíritu de la democracia dentro de las cooperativas, una tarea sin fin, difícil, valiosa e incluso esencial.

Las cooperativas son organizaciones gestionadas democráticamente por los socios, los cuales participan activamente en la fijación de sus políticas y en la toma de decisiones. Además, en todas las cooperativas los hombres y mujeres elegidos para representar y gestionar las cooperativas son responsables ante los socios, lo cual significa que las cooperativas pertenecen a los socios, y todos los dirigentes tienen que responder de sus acciones, en el momento de la elección y durante su mandato, ante los socios.

En las cooperativas de un grado, los socios tienen iguales derechos de voto -un socio, un voto-, y las cooperativas de otros grados, están también organizadas de forma democrática.

Por "participación económica de los socios", se entiende que los mismos contribuyen equitativamente al capital de sus cooperativas y lo gestionan de forma democrática. Parte de ese capital es propiedad común de la cooperativa. De ordinario los socios reciben una compensación, si la hay, limitada sobre el capital entregado como condición para ser socio. Los mismos, asignan los excedentes para todos o alguno de los siguientes fines: el desarrollo de su cooperativa, el beneficio de los socios en proporción a sus operaciones con la cooperativa, y el apoyo de otras actividades aprobadas por los socios.

En tal sentido, las cooperativas funcionan de forma que el capital es el sirviente y no el amo de la organización, existe para satisfacer las necesidades de la gente.

- "Autonomía e independencia": las cooperativas en todas partes del mundo están muy afectadas por sus relaciones con el Estado. Los gobiernos determinan el marco legislativo dentro del cual las cooperativas pueden funcionar. En sus políticas fiscales, económicas y sociales, los gobiernos pueden ayudar o perjudicar a las cooperativas. Por esa razón, todas las cooperativas deben estar alertas para desarrollar relaciones claras y abiertas con los gobiernos.

El principio dice que las cooperativas son organizaciones autónomas de autoayuda, gestionadas por sus socios. Si firman acuerdos con otras organizaciones, incluidos los gobiernos, o si consiguen capital de fuentes externas, lo hacen en términos que aseguren el control democrático por parte de sus socios y mantengan su autonomía cooperativa.

- "Educación, formación e información": este principio alude a que las cooperativas deben proporcionar educación y formación tanto a los socios, como a los representantes elegidos, a los directivos y empleados, con el fin de que puedan contribuir de forma eficaz al desarrollo de sus cooperativas. Informan al público, especialmente a los jóvenes y a los líderes de opinión, de la naturaleza y beneficios de la cooperación.

Publicado en formato digital: Mgter. Viviana Claudia Pertile. LAS COOPERATIVAS EN EL CONTEXTO DE LAS ORGANIZACIONES DE LA ECONOMÍA SOCIAL: BREVE RESEÑA HISTÓRICA. CARACTERÍSTICAS GENERALES. Revista Geográfica Digital. IGUNNE. Facultad de Humanidades. UNNE. Año 10. No 20. Julio Diciembre 2013. ISSN 1668-5180 Resistencia, Chaco. En: http://hum.unne.edu.ar/revistas/geoweb/default.htm 
Con este principio queda enfatizada la vital importancia de la educación y la formación dentro de las cooperativas. Siendo la educación algo más que la simple distribución de información o el fomento de ser usuario, significa comprometer a las mentes de los diferentes actores involucrados, para que entiendan bien la complejidad y riqueza del pensamiento y acción cooperativos. Por su parte, la formación, significa asegurar que todos los que están implicados en las cooperativas tengan las habilidades necesarias para llevar a cabo sus responsabilidades eficazmente.

- "Cooperación entre cooperativas": las cooperativas sirven a sus socios lo más eficazmente posible y fortalecen el movimiento cooperativo trabajando conjuntamente mediante estructuras locales, nacionales, regionales e internacionales. Las cooperativas solo pueden maximizar su impacto mediante la colaboración práctica y rigurosa la una con la otra. Deben reconocer la necesidad de reforzar sus organizaciones y actividades de apoyo.

- "Interés por la comunidad": recordemos que las cooperativas son organizaciones que existen principalmente para el beneficio de sus socios, y en este sentido, también están estrechamente ligadas a sus comunidades. De allí que tienen la responsabilidad de asegurar que se sostenga el desarrollo de sus comunidades, económica, social y culturalmente. Tiene la responsabilidad de trabajar a un rimo constante para la protección medioambiental de esas comunidades. Sin embargo, los socios tiene que decidir en qué profundidad y de qué forma específica una cooperativa debe hacer sus aportaciones a su comunidad. No es, sin embargo, un conjunto de responsabilidades que los socos puedan obviar.

Es a partir de lo expuesto, que el presente trabajo recoge esta temática en un intento por avanzar en los orígenes del cooperativismo en la Argentina y en la provincia del Chaco.

\section{Los inicios del Cooperativismo en la Argentina y en el Chaco.}

A lo largo de la historia, el cooperativismo en Argentina se ha desarrollado en todas sus formas, respondiendo a diferentes momentos socio-económicos y problemas institucionales del país. Para miles de habitantes de nuestro país, hablar de cooperativas significa referirse a la luz, el teléfono, el gas, la vivienda, el agua, el crédito o el trabajo. Fundamentalmente en el interior, en las zonas rurales y en las pequeñas y medianas localidades alejadas de los grandes centros urbanos, el rol de estas entidades fue y es fundamental para su desarrollo económico y social.

Existe una amplia gama de cooperativas que fueron difundiéndose a través del tiempo. Desde el Punto de vista del nivel de agrupación, podemos encontrarnos con las denominadas Cooperativas de "Primer Grado"; las de "Segundo Grado" y las de "Tercer Grado" (7) ${ }^{4}$.

El desarrollo y funcionamiento del Cooperativismo Europeo del siglo XIX, producto de la reacción popular frente a las situaciones de injusticia y abuso, nacidas de las condiciones imperantes de la época, fue pronto conocido en Argentina, a través de las ideas expuestas por los inmigrantes llegados a la República Argentina. (Drimer y Drimer, op. cit.).

Se puede decir que las cooperativas agrarias comenzaron a surgir con mayor fuerza durante las primeras décadas del siglo XX, fundamentalmente cuando las condiciones económicas de la actividad agropecuaria se hicieron más difíciles. Los problemas por los que atravesaban muchos productores no los podían sortear sino por medio de la solidaridad.

En nuestro país, la creación de cooperativas responde a dos tipos de prácticas diferentes. Por un lado, se encontraban las creadas por sectores obreros con el fin de liberarse o, por lo menos, aminorar los efectos de la explotación capitalista. Por el otro,

Publicado en formato digital: Mgter. Viviana Claudia Pertile. LAS COOPERATIVAS EN EL CONTEXTO DE LAS ORGANIZACIONES DE LA ECONOMÍA SOCIAL: BREVE RESEÑA HISTÓRICA. CARACTERÍSTICAS GENERALES. Revista Geográfica Digital. IGUNNE. Facultad de Humanidades. UNNE. Año 10. No 20. Julio Diciembre 2013. ISSN 1668-5180 Resistencia, Chaco. En: http://hum.unne.edu.ar/revistas/geoweb/default.htm 
aquellas que fueron originadas por integrantes de la clase media y clase media alta, para poder desarrollar su actividad comercial o industrial, enfrentando a las grandes empresas monopólicas, la banca extranjera y las dificultades económicas.

Las primeras experiencias de cooperativas registradas en Argentina, datan de fines de los años 1880. En el año 1884, se creó la Sociedad Cooperativa de Almacenes, cuyo fin era el de abastecer inicialmente comestibles y bebidas, para abarcar luego otros ramos del comercio o la industria. Su fundador fue un argentino, hijo de británicos, el señor David H. Atwel. Un año más tarde, en 1885 se fundó la Compañía Mercantil del Chubut, por un grupo de colonos galeses, en la ciudad de Trelew. Se propuso colocar en condiciones convenientes la producción de sus asociados y proveerlos de diversos artículos.

Posteriormente, en el año 1898, se funda la cooperativa "El Progreso Agrícola, de Pigüé (8) ". En el mismo año, pero en la provincia de Buenos Aires se funda la "Cooperativa Obrera de Consumos", fundada por el Dr. Juan B. Justo (9). Esta cooperativa no prosperó y al cabo de tres años desaparece.

A principios del año 1900 se funda "La Agrícola Israelita, denominada luego "Sociedad Agrícola de Lucienville" (10), en Basavilbaso, Entre Ríos. Inicialmente no fue una cooperativa, sino una mutual, pero sirvió de modelo para la mayoría de las cooperativas argentinas llamadas mixtas.

En el año 1904, se crea la primera cooperativa agraria propiamente dicha, la "Liga Agrícola Ganadera" en Junin", provincia de Buenos Aires, con el objeto de proteger a los productores de la zona, constituyéndose posteriormente en una importante cooperativa agraria multifuncional, que proporcionaba a sus socios, la colocación de la producción, provisión, consumo, créditos, etc. En ese mismo año se funda en Entre Ríos otra cooperativa agraria "Fondo Comunal, Sociedad Cooperativa limitada" en Colonia Clara, Villa Domínguez en la provincia de Entre Ríos; ésta, de alguna manera se constituyó en el eje del cooperativismo entrerriano.

Dentro de las entidades precursoras del cooperativismo en la Argentina, no debemos dejar de mencionar a la "Cooperativa Agrícola Algodonera Ltda. de Colonia Margarita Belén, fundada en el año 1905, en la localidad homónima, en la Provincia del Chaco, más adelante pasaría a llamarse "Cooperativa Agrícola Algodonera El Triunfo Ltda."En este mismo año creó "El Hogar Obrero". Fundada por iniciativa del Dr. Juan B. Justo y con la valiosa colaboración del Dr. Nicolás Repetto y de otro pequeño grupo de personas. Se realizó una obra de extraordinarias proyecciones, no sólo por su desarrollo material sino por su aporte a la difusión de las prácticas cooperativas. El objeto de la sociedad era proporcionar crédito a sus asociados para la adquisición de sus casas y para otros fines.

En el año 1913 surge la primera cooperativa de segundo grado o cooperativa de cooperativas, como se las llamó inicialmente. La Confederación Entrerriana de Cooperativas (de la provincia de Entre Ríos), refundada en 1933 con el actual nombre de Federación Entrerriana de Cooperativas.

En 1922 se e creó la "Asociación de Cooperativas Rurales Zona Central", origen de la actual "Asociación de Cooperativas Argentinas, Cooperativa Ltda." (ACA). Esta se constituye en la más antigua federación argentina de funcionamiento ininterrumpido. En un principio agrupó a varias cooperativas de las provincias de Córdoba y Santa Fe, extendiendo luego su radio de acción.

A partir de las décadas siguientes el sector cooperativo se consolidó y expandió como una forma diferente de organización, más solidaria y equitativa, ocupando un lugar prestigioso en el desarrollo de nuestro país. Surgieron las cooperativas de tercer grado: CONINAGRO (Confederación Intercooperativa Agropecuaria Cooperativa Limitada) y COOPERAR (Confederación Cooperativa de la República Argentina Limitada), en 1956 y 1962, respectivamente. (Montes y Ressel, 2003)

Publicado en formato digital: Mgter. Viviana Claudia Pertile. LAS COOPERATIVAS EN EL CONTEXTO DE LAS ORGANIZACIONES DE LA ECONOMÍA SOCIAL: BREVE RESEÑA HISTÓRICA. CARACTERÍSTICAS GENERALES. Revista Geográfica Digital. IGUNNE. Facultad de Humanidades. UNNE. Año 10. No 20. Julio Diciembre 2013. ISSN 1668-5180 Resistencia, Chaco. En: http://hum.unne.edu.ar/revistas/geoweb/default.htm 
En la década del setenta hubo cierto estancamiento y retraso en el movimiento cooperativo.

En los años ochenta con el retorno de la democracia, las cooperativas "florecieron" nuevamente y comenzaron a expandirse.

La situación de las cooperativas presentó en la década del 90 una serie de aspectos complejos. En este sentido, Montes y Ressel, 2003 señalan: las privatizaciones generaron un ingreso de capitales desmedidos y de empresas interesadas únicamente en el lucro, dejando un campo pequeño para las cooperativas, por la eficiencia que se necesitó y por desechar solo las áreas donde no existió la llamada eficiencia económica; asimismo, el aumento constante del desempleo en el país, permitió que un modelo surgiera cada vez con mayor fuerza. Así, las cooperativas de trabajo se expandieron en las diferentes provincias, representando aproximadamente el $35 \%$ del total de cooperativas a mediados de la década del 90. Además, en estos años a nivel internacional la Alianza Cooperativa Internacional (A.C.I) reformuló la definición de cooperativa y sus principios, generando una externalidad positiva en lo referente a identidad.

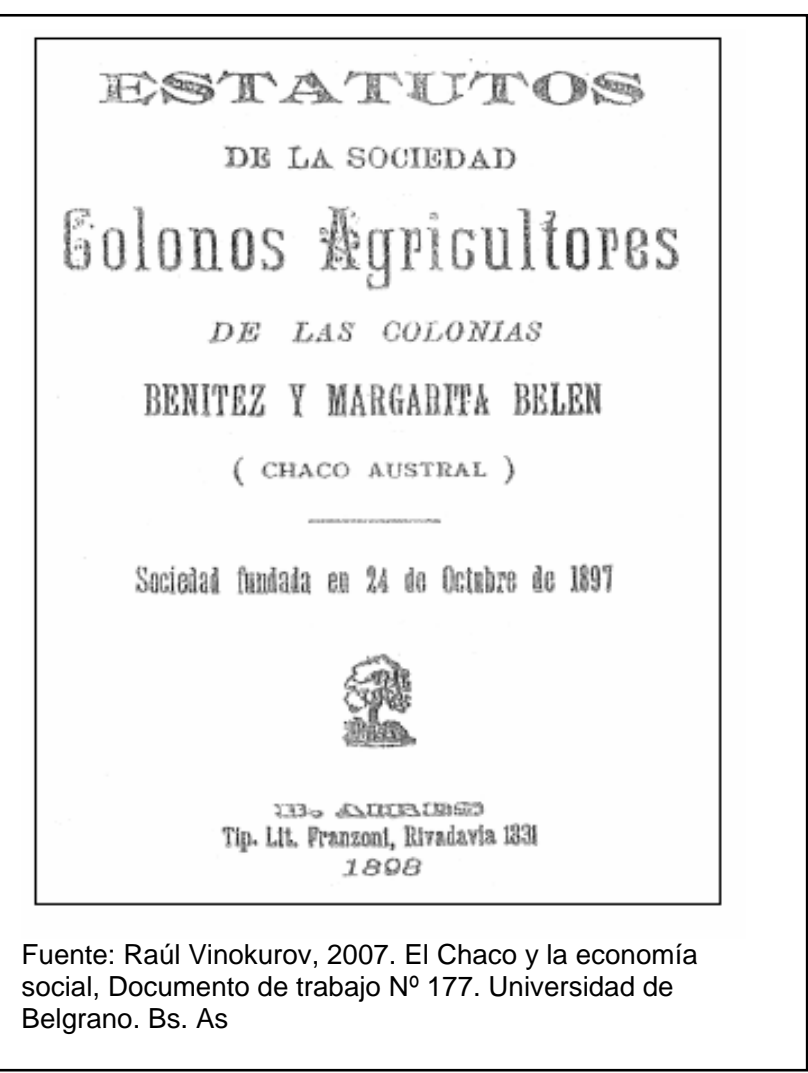

Esta suma de variables determinó que su accionar se torne relevante tras la crisis generada por el neoliberalismo, que produjo un importante deterioro en la calidad de vida de los pueblos, retroceso en la distribución del ingreso, acelerada desocupación y dependencia económica a grandes capitales. La crisis puso en evidencia la incapacidad de ese modelo en materia de protección social de la población y, en este contexto, las cooperativas han demostrado ser más resistentes.

\section{El Cooperativismo en el Chaco}

El desarrollo del cooperativismo se dio básicamente a raíz de la necesidad de los productores por mejorar y asegurar sus productos, insumos, precio y conseguir la propiedad de las tierras. Asimismo, las cooperativas agrarias han podido cubrir diversas actividades, necesidades o servicios, tales como el aprovisionamiento, la producción, la transformación y la comercialización. No obstante, el sistema cooperativo de finales del siglo XIX, que tuvo un importante desarrollo dentro del modelo de sustitución de importaciones; en la década de 1990 ya no podía ser percibido como un instrumento adecuado para competir en forma eficiente en el escenario contemporáneo. Distintas experiencias internacionales desarrolladas durante las dos últimas décadas del siglo XX orientaron acerca de la dirección a seguir y, al mismo tiempo, determinaron en el movimiento cooperativo una situación de crisis: un estado de cambios profundos en la organización así como la puesta en debate de principios fundacionales de su doctrina. (Lattuada y Renold, 2004).

Publicado en formato digital: Mgter. Viviana Claudia Pertile. LAS COOPERATIVAS EN EL CONTEXTO DE LAS ORGANIZACIONES DE LA ECONOMÍA SOCIAL: BREVE RESEÑA HISTÓRICA. CARACTERÍSTICAS GENERALES. Revista Geográfica Digital. IGUNNE. Facultad de Humanidades. UNNE. Año 10. № 20. Julio Diciembre 2013. ISSN 1668-5180 Resistencia, Chaco. En: http://hum.unne.edu.ar/revistas/geoweb/default.htm 
La primer expresión del cooperativismo fue la Sociedad de colonos Agricultores de Colonia Benítez y Margarita Belén, fundada en enero de 1897, cuyo objetivo fue el de defender la producción agrícola de la de la zona, como así también la compra y venta de los mismos, de los intereses económicos que comenzaban a instalarse en cercanías de estas localidades. Pese a haber alcanzado una cierta organización, esta sociedad se disolvió, debido a los intereses existentes en el ámbito empresarial, que no se veían favorecidos con la organización de los colonos. Bs. As Pese a ello, en 1905 se fundó la Sociedad de Cooperativa Familiar de Margarita Belén, constituida por a lo sumo 20 socios, pequeños productores propietarios de sus tierras, quienes se propusieron llevar adelante la explotación de productos agrícolas y el negocio de artículos en general. Lo primero que realizaron fue la construcción de un galpón de con techo de zinc, se compró una desmotadora simple, una prensa fija a tornillo y un motor de 12 HP. Con estas Fuente: Raúl Vinokurov, 2007. El Chaco y la economía social, Documento de trabajo $N^{\circ} 177$. Universidad de Belgrano.instalaciones, la institución funcionó no por mucho tiempo; múltiples fueron los factores que determinaron el fracaso de esta primera Cooperativa familiar, entre los cuales podemos citar la baja de los precios y por ende escaso interés en el algodón, falta de dirección eficaz, entre otros. (Miranda, 1984).

A principios de 1919 se constituye en Margarita Belén una nueva entidad cooperativa en el Chaco, la Cooperativa Agrícola Industrial de Margarita Belén, teniendo por ese año como único objetivo el desmote de algodón de sus asociados, a fin de presentar al mercado fibra y semilla por separado y no algodón en bruto; a esta cooperativa se incorporaron los antiguos socios de la Cooperativa Familiar.

También en el año 1919 debemos mencionar otras cooperativas fundadas en el Territorio del Chaco, entre las que se citan a la Sociedad de Fomento Agrícola de Puerto Tirol.; la Sociedad Unión de Agricultores y Ganaderos de Presidencia de la Plaza; la Sociedad Agraria de Quitilipi; la Sociedad Agraria de Las Palmas.

Más tarde se siguieron creando varias en el interior del Territorio. En 1941 funcionaban 18 cooperativas algodoneras de las cuales 14 contaban con su propia desmotadora y estaban distribuidas en las principales localidades de la zona productora: Presidencia Roque Sáenz Peña, Machagai, Las Breñas, Charata, Villa Ángela, Quitilipi, Castelli. Entre ellas podemos mencionar: En la Colonia Presidencia Roque Sáenz Peña la Cooperativa Algodonera de Presidencia Roque Sáez Peña; en 1925, En la localidad de Charata, la Cooperativa Agrícola; En Quitilipi, se conformará la Asociación Cooperativa de Agricultores Algodoneros; En Villa Ángela, la Cooperativa Agrícola de Villa Ángela; En Las Breñas se formará la Cooperativa Agrícola Las Breñas; En Machagai, la Cooperativa Agrícola de Machagai, En General Vedia, la Cooperativa agrícola.(Moglia, 2006).

Al respecto (Maeder, 1997) manifiesta "la sola enunciación de estos lugares en el interior, evidencia la formación y crecimiento de los pueblos, así como la transformación a que se asistía en la producción y en la vida social del Territorio. Pueblos y colonias, cooperativas, desmotadoras, aceiterías, ferrocarriles y movimiento comercial, son parte de los rasgos que caracterizaba este frente pionero que comenzaba a modificar, radicalmente, la fisonomía del Chaco agreste y temido del pasado".

No todos estos emprendimientos pudieron mantenerse en el tiempo, entre las causas de la desaparición de muchas de ellas, podemos mencionar los bajos rendimientos de las cosecha; la baja en la cotización de la fibra de algodón, situación que determinó, en su momento, la reducción en las superficies sembradas.

Este panorama de crecimiento y desarrollo de las cooperativas en la provincia del Chaco, nos habla a las claras de la posición que ocupaba la misma.

Si bien es cierto que las cooperativas tuvieron momentos de esplendor y retrocesos, Según datos del Instituto Nacional de Asociativismo y Economía Social (INAES), para el año

Publicado en formato digital: Mgter. Viviana Claudia Pertile. LAS COOPERATIVAS EN EL CONTEXTO DE LAS ORGANIZACIONES DE LA ECONOMÍA SOCIAL: BREVE RESEÑA HISTÓRICA. CARACTERÍSTICAS GENERALES. Revista Geográfica Digital. IGUNNE. Facultad de Humanidades. UNNE. Año 10. No 20. Julio Diciembre 2013. ISSN 1668-5180 Resistencia, Chaco. En: http://hum.unne.edu.ar/revistas/geoweb/default.htm 
2005 la cantidad de cooperativas existentes en la provincia del Chaco alcanzaba a 377 siendo las de trabajo (185), las agropecuarias (52), las de previsión (52), las de vivienda (46) y las de servicios públicos (28) las principales actividades que desarrollan (Vinokurov, 2007).

¿Cuál es la situación a principios de la década del 2010 en la provincia del Chaco? Podríamos decir que el sistema cooperativo chaqueño, que llegó a ser el orgullo y una marca registrada en la provincia, hoy se debilita. Subsisten solo algunas que se niegan a que el espíritu de Rochdale desaparezca del territorio provincial.

Sin embargo y de acuerdo a los datos proporcionados por el Instituto Nacional de Economía Social de y Asociativismo (INAES), la situación en el país es diferente, por cuanto muchas personas eligen este sistema para enfrentar sus desafíos. Existen en Argentina alrededor de 8300 cooperativas (sin considerar las mutuales) de las cuales 377 se localizan en la provincia del Chaco, ocupando el undécimo lugar a nivel nacional.

\section{Tendencias Actuales}

Tal cual lo dijéramos al inicio de esta primera parte, las cooperativas nacen por la necesidad que tuvieron de los productores de superar diferentes situaciones, que por sí solo no lo podían resolver. Conformándose entidades que proporcionaron representación institucional a una importante masa de productores en muchas regiones del mundo e inclusive de Argentina.

La situación ha cambiado desde el año 1844 en Inglaterra, cuando la necesidad económica obligó a trabajadores de Rochadle, ciudad situada en el condado Inglés de Lancashire, a concretar el primer intento cooperativo. En la actualidad estas Instituciones han evolucionado y se fortalecieron mediante nuevas formas de organización, participación y educación; cambios que también se vieron reflejados en nuestro país, donde el desafío actual consiste es darle valor agregado a la producción. En este sentido existe coincidencia entre algunas entidades cooperativas y el gobierno nacional de comenzar a transformar las materias primas en los lugares en los que se produce y de esta manera comenzar con la industrialización regional, logrando de esta manera la generación de nuevos empleos.

El camino del nuevo cooperativismo estará dado sin dudas por la modernización, la que deberá estar acompañada por la educación, apoyada en los principios de fundamentales del asociativismo, donde los socios tengan no solo derechos sino también obligaciones para que las cooperativas puedan cumplir con la comercialización y la industrialización tan ansiada y de esa manera las entidades puedan salir adelante, renovadas y con los problemas resueltos.

\section{Conclusiones}

A lo largo de la historia, el cooperativismo se ha desarrollado en todas sus formas y respondiendo a diferentes momentos socio-económicos. Para cientos de personas hablar de cooperativas significó utilización de la luz eléctrica, el teléfono, el gas, la vivienda, el agua, el crédito o el trabajo. Fundamentalmente en el interior, en las zonas rurales y en las pequeñas y medianas localidades alejadas de los grandes centros urbanos, el rol de estas entidades fue y es fundamental para su desarrollo económico y social de bastas regiones del planeta.

Hoy, más que nunca esta importante organización de la Economía Social, con un rol fundamental en la estructura productiva regional, debe buscar que los principios cooperativos de la participación económica de los asociados, con una adecuada gestión democrática, la autoayuda y la solidaridad le provean de las fuerzas necesarias para sobrevivir en un contexto hostil para este tipo de organizaciones, caso contrario no podrá superar sus limitaciones y se verá condenada a la desaparición con la consecuente afectación a la gran masa de productores que, aunque no lo vean claramente, se quedan sin su principal herramienta de supervivencia en un mundo hipercompetitivo y eficientista.

En el caso de la cooperativa, objeto de nuestra investigación, entre los principios cooperativos más afectado, probablemente siempre fue el de autonomía e independencia.

Publicado en formato digital: Mgter. Viviana Claudia Pertile. LAS COOPERATIVAS EN EL CONTEXTO DE LAS ORGANIZACIONES DE LA ECONOMÍA SOCIAL: BREVE RESEÑA HISTÓRICA. CARACTERÍSTICAS GENERALES. Revista Geográfica Digital. IGUNNE. Facultad de Humanidades. UNNE. Año 10. № 20. Julio Diciembre 2013. ISSN 1668-5180 Resistencia, Chaco. En: http://hum.unne.edu.ar/revistas/geoweb/default.htm 
En este sentido, la esperanza en la acción salvadora del Fondo Especial del Tabaco para cubrir todos los déficit operativos y económicos que genera la actividad, dejaron sin defensas apropiadas a la estructura cooperativa que se hace difícil regenerar en un ambiente de crisis y con escasos mecanismos de activa participación del asociado, lo que también evidencia que el principio de la educación, formación e información de sus asociados no ha sido eficientemente fortalecido.

\section{NOTAS}

1.- El sistema cooperativo nació en el año 1844 en Inglaterra, fruto de un proceso puramente económico y estrechamente relacionado con el industrialismo Ingles. La necesidad económica obligo a trabajadores de Rochadle, ciudad situada en el condado Inglés de Lancashire, a concretar el primer intento cooperativo de consumo, mediante la instalación de un almacén.

2.- Charles Gide, citado En: Grela, 1965

3.- Publicó en 1822 su obra principal "tratado de asociación doméstica agrícola", en la que expuso ideas acerca de las "falanges" y los "falansterios". Los primeros eran agrupaciones de aproximadamente 1500 a 2000 personas, pertenecientes a todos los niveles sociales. Estas personas habitarían en establecimientos denominados falansterios, que tendrían un núcleo central, donde a manera de un gran hotel, daría albergue y comida a los asociados, contando para ello con habitaciones o departamentos adecuados, comedores comunes, salas de lecturas, de juego, de teatro y demás instalaciones sociales. (Drimer y Drimer Op. Cit)

4.- En Brown L.; Craig, J; Ketilson, L. (op. cit.).

5.- En Brown L.; Craig, J; Ketilson, L. (op. cit.).

6.- ICA (1995). Declaración de la Alianza Cooperativa Internacional sobre la identidad Cooperativa. Los principios cooperativos. Edición del Consejo Superior de Cooperativas de Euskadi.

7.- En las Cooperativas de Primer grado sus asociados son personas físicas o jurídicas de cualquier tipo. Salvo las Cooperativas de trabajo de primer grado que solo pueden asociar personas físicas. Las Cooperativa de Segundo Grado sus asociados son cooperativas de primer grado y forman Federaciones, cuyo propósito puede ser la representación gremial o sectorial, ó complementar e integrar las actividades de sus asociados para el mejor cumplimiento de sus fines económicos, sociales y culturales. Ej. Asociación de Cooperativas Argentinas, Cooperativa Ltda." (ACA). Las de Tercer Grado están constituida por cooperativas de segundo grado, y realizan la representación institucional del sector y la defensa de sus intereses y pueden promover actividades de tipo económico, Ej. CONINAGRO (Confederación Intercooperativa Agropecuaria Cooperativa Limitada)

8.- Localidad situada al Sur de la Provincia de Buenos Aires

9.- El Dr. Juan B. Justo, propició la organización de cooperativas a los efectos de mejorar las condiciones de vida de la población. Esta cooperativa se instalo en la ciudad de Buenos Aires y se proa uso suministrar a sus asociados toda clase de artículos de consumo.(Drimer y Drimer op.cit)

10.- Esta entidad se propone colocar las cosechas de sus asociados y proveer los artículos requeridos por ellos en condiciones convenientes, además de organizar cajas de ahorros y préstamos y de difundir conocimientos técnicos sobre agricultura.(Drimer y Drimer op.cit)

Publicado en formato digital: Mgter. Viviana Claudia Pertile. LAS COOPERATIVAS EN EL CONTEXTO DE LAS ORGANIZACIONES DE LA ECONOMÍA SOCIAL: BREVE RESEÑA HISTÓRICA. CARACTERÍSTICAS GENERALES. Revista Geográfica Digital. IGUNNE. Facultad de Humanidades. UNNE. Año 10. No 20. Julio Diciembre 2013. ISSN 1668-5180 Resistencia, Chaco. En: http://hum.unne.edu.ar/revistas/geoweb/default.htm 
Revista Geográfica Digital. IGUNNE. Facultad de Humanidades. UNNE. Año 10. № 20.

Julio - Diciembre 2013. ISSN 1668-5180 Resistencia, Chaco

\section{Bibliografía}

BROW, L. CRAIG, J. y KETILSON, L. (1995) Cómo dar significado a la participación. La democracia participativa en las cooperativas. Intercoop Editoria Cooperativa Ltda. Buenos Aires.

CRACOGNA, Dante (1985) Comentarios a la Ley de Cooperativas, Ediciones Intercoop, Buenos Aires.

DRIMER, B. y DRIMER, A.K. (1987) Compendio de Cooperativas, Ediciones Intercoop. Segunda Edicion, Buenos Aires.

DRIMER, Bernardo y DRIMER, KAPLAN, Alicia de (1981): "Las Cooperativas. Fundamentos-Historia-Doctrina". Ediciones Intercoop Edit. Coop. Ltda., $3^{a}$ edición, Bs. As., FAIRBAIRN, en BROWN L.; CRAIG, J; KETILSON, L. (1995). Cómo dar significado a la participación. La democracia participativa en las cooperativas. Intercoop Editora Cooperativa Ltda. Buenos Aires.

GIDE, Charles (1958): Curso de economía política, Ed. El Ateneo, Bs. As.

GRELA, Placido (1965): Cooperativismo y Monopolio. Ed. Platina, Bs.As.

ICA (1995). Declaración de la Alianza Cooperativa Internacional sobre la identidad Cooperativa. Los principios cooperativos. Edición del Consejo Superior de Cooperativas de Euskadi.

JENEFES, Víctor y LACLAU, Edim. Margarita Belén, Cuna del Cooperativismo Agrícola; Resistencia, SELCH; 1992 (en Moglia, mesa 12)

KESSELMAN, Julio (1979): Sociedades cooperativas. Ed. Victor P. de Zavalia, Bs.As.

LATTUADA, Mario y RENOLD, Juan M. (2004): El Cooperativismo agrario ante la globalización. Un análisis sociológico de los cambios en su composición, morfología y discurso institucional. Ed. Siglo Veintiuno editores argentinos. 2004. Buenos Aires.

LEVIN, Andrea y VERBEKE, Griselda (1997). El Cooperativismo Argentino en Cifras. Tendencias en su evolución: 1927-1997, Argentina, E.F.C.E. UBA. Bs.

MAEDER, Ernesto (1997).: Historia del Chaco, Editorial Plus Ultra, Buenos Aires, Argentina MICHELSEN, J. (1997) "Las Lógicas de las organizaciones cooperativas. Algunas sugerencias desde la realidad escandinava." Centro de Estudios de Sociología del Trabajo. Doc. N ${ }^{\circ} 2$, UBA, Fac. de Ciencias Económicas.

MIRANDA, Guido, 1984: Historia del Cooperativismo Chaqueño. Basamento de la integración y el progreso provincial. Fundación Cosecha. Resistencia-Chaco

MOGLIA, Leandro (2006): Origen y Evolución Histórica del Cooperativismo Agrícola en el Territorio Nacional del Chaco hasta 1930. En Jornadas de Historia Económica, Mar del Plata, Bs. As. 2006.

MONTES, Verónica y RESSEL, Alicia. "Presencia del Cooperativismo en Argentina", en revista UNIRCOOP, Volumen 1, número 2, páginas 9 a 26, editorial IRECUS, Cuarto Trimestre 2003.

MONZÓN, J. L., DEFOURNY, J. (1987) Economía Social. Entre economía capitalista y economía pública, CIRIEC, Valencia.

REFORMA de la Ley de Cooperativas 1995. Informe de la Comisión sobre propuestas de reformas a la Ley 20.337. Intercoop Editora Coop. Ltda.

SANPEDRO, José (1987) Manual de Organización y Gestión Cooperativa, Ediciones Intercoop. Buenos Aires.

STRYJAN, Yohanan (1992) "Comprendiendo a las cooperativas". Centro de Estudios de Sociología del trabajo. Buenos Aires. Documento 9.

VACAREZZA, Juan Carlos (1976) Manual Administrativo, Contable, Impositivo y Legal para Cooperativas, Editorial Cangallo, Buenos Aires.

VINOKUROV, Raúl (2007) El Chaco y la economía social, Documento de trabajo № 177. Universidad de Belgrano. Bs. As.

Publicado en formato digital: Mgter. Viviana Claudia Pertile. LAS COOPERATIVAS EN EL CONTEXTO DE LAS ORGANIZACIONES DE LA ECONOMÍA SOCIAL: BREVE RESEÑA HISTÓRICA. CARACTERÍSTICAS GENERALES. Revista Geográfica Digital. IGUNNE. Facultad de Humanidades. UNNE. Año 10. No 20. Julio Diciembre 2013. ISSN 1668-5180 Resistencia, Chaco. En: http://hum.unne.edu.ar/revistas/geoweb/default.htm 
Revista Geográfica Digital. IGUNNE. Facultad de Humanidades. UNNE. Año 10. № 20.

Julio - Diciembre 2013. ISSN 1668-5180 Resistencia, Chaco

\section{SITIOS WEB}

- $\quad$ www.mecon.gov.ar

- - www.sagpya.mecon.gov.ar

- - www.mecon.gov.ar/hacienda

- $\quad$ www.coprotab.com

- $\quad$ www.noblezapiccardo.com

- $\quad$ www.cfired.org.ar

- - www.mininterior.gov.ar

- $\quad$ www.usda.gov

- $\quad$ www.who.org

- $\quad$ www.inversiones.gov.ar 